\title{
Influence of Sintering Time on the PTCR Effect of $\mathrm{Nb}_{2} \mathrm{O}_{5}$-doped $\mathrm{BaTiO}_{3}$ Ceramics
}

\author{
Xuxin Cheng ${ }^{a} \oplus$, Haining Cui ${ }^{a}$, Zhiyong X $u^{a}$, Xiaoming Chen ${ }^{a *}$, Yuxin Wang ${ }^{b}$ \\ ${ }^{a}$ School of Electronic and Electrical Engineering, Zhaoqing University, Zhaoqing Road, Duanzhou \\ District, Zhaoqing 526061, Guangdong, PR China \\ ${ }^{b}$ School of Materials Science and Engineering, Jiangsu University of Science and Technology, \\ Zhenjiang 212003, Jiangsu, PR China
}

Received: November 28, 2018; Revised: June 26, 2019; Accepted: July 02, 2019

\begin{abstract}
The effects of the sintering time on the electrical properties and the positive temperature coefficient of resistance (PTCR) effect of $\mathrm{Ba}_{1.006}\left(\mathrm{Til}_{\mathrm{x}} \mathrm{Nb}_{\mathrm{x}}\right) \mathrm{O}_{3}(\mathrm{BTN})$ ceramics were investigated, which were sintered at $1190{ }^{\circ} \mathrm{C}$ for $0.5-6$ hours in a reducing atmosphere and then re-oxidized at $800{ }^{\circ} \mathrm{C}$ for 1 hour. The results indicated that the sintering time affected the electrical properties and the PTCR effect of the multilayer BTN samples, whose room-temperature resistance decreased with an increase of the sintering time at same sintering temperature of $1190^{\circ} \mathrm{C}$. However, the resistance jump first increased and then reduced as a function of the sintering time. Furthermore, The BTN ceramics exhibited a pronounced PTCR effect, with a resistance jump greater by 3.6 orders of magnitude, along with a low RT resistance of $0.14 \Omega$ at a reoxidated temperature of $800^{\circ} \mathrm{C}$ after sintering at $1190{ }^{\circ} \mathrm{C}$ for $2 \mathrm{~h}$ in a reducing atmosphere. In addition, the activation energy of samples obtained at different sintering times had also been investigated.
\end{abstract}

Keywords: $\mathrm{BaTiO}_{3}$, $\mathrm{PTC}$ effect, $\mathrm{Nb}_{2} \mathrm{O}_{5}$-dopant, Reoxidation.

\section{Introduction}

It is well-known that barium titanate can undergo phase transition from tetragonal to cubic structures ${ }^{1}$. Replacing of $\mathrm{A}$ or $\mathrm{B}$ sites in $\mathrm{BaTiO}_{3}\left(\mathrm{ABO}_{3}\right)$ with trivalent donors or pentavalent impurities, respectively increases the positive temperature coefficient of resistance (PTCR) effect of this material ${ }^{2,3}$, as reported by Heywang ${ }^{4,5}$ and Jonker ${ }^{6}$. According to a proposed model, the PTCR effect of positive temperature coefficient (PTC) ceramics can be considered a grain-boundary effect.

PTCR thermistors are usually used in low-voltage integrated circuits as overcurrent-protection elements. At present, elements with ever-decreasing room-temperature (RT) resistance are required. However, the RT resistance of ceramics can be hardly reduced with traditional preparation methods. In this sense, the RT resistance of ceramics has been reduced by sintering these materials with a reduction/re-oxidation method, which led to a laminated chip-type structure ${ }^{7,8}$.

Recently, Lin et al. ${ }^{9}$ reported that the electrical properties of two categories of samples were affected by the soaking time. Lu et al. ${ }^{10}$ found that the RT resistivities of ceramic samples increased with the soaking time, mostly as a result of the increase in the grain-boundaries resistivities. In addition, according to Al-Allak et al. ${ }^{11}$, the PTCR effect is affected by the interfacial segregation of cation vacancies. Ho et al. ${ }^{12}$ found that the acceptor-state density depends on the annealing time. Langhammer et al. ${ }^{13}$ suggested that the potential barrier height can be enhanced during the cooling process.
However, the influence of the sintering time on the PTCR and electrical properties of $\mathrm{Ba}_{1.006}\left(\mathrm{Ti}_{1-x} \mathrm{Nb}_{x}\right) \mathrm{O}_{3}(\mathrm{BTN})$ ceramics sintered in reducing atmospheres has been scarcely described in the literature. Therefore, the electrical and PTCR properties of BTN samples prepared by the reduction/re-oxidation method were investigated in this paper.

\section{Material and Methods}

The starting materials were high-purity $\mathrm{BaCO}_{3}(>99.8 \%)$, $\mathrm{TiO}_{2}(>99.8 \%), \mathrm{Nb}_{2} \mathrm{O}_{5}(>99.99 \%)$, and $\mathrm{SiO}_{2}(>99.99 \%)$. The amounts of the different materials were calculated for a formula $\mathrm{Ba}_{1.006}\left(\mathrm{Ti}_{1-x} \mathrm{Nb}_{x}\right) \mathrm{O}_{3}+0.05 \mathrm{~mol} \% \mathrm{SiO}_{2}(\mathrm{BTN})$, where $x$ is $0.35 \mathrm{~mol} \%$. These materials were mixed by high-energy ball milling for $90 \mathrm{~min}$ ( $2400 \mathrm{rpm}$ ) in deionized water using zirconia balls and subsequently calcined at $1150{ }^{\circ} \mathrm{C}$ for $2 \mathrm{~h}$ in air. After drying and sieving steps, the calcined powder was ground again using wet ball milling for $5 \mathrm{~h}$ in a polyurethane jar. Next, the dried powder was blended with dispersant, solvent, binder, and defoamer agents via ball milling for 18 $\mathrm{h}$ in a nylon pot. The mixture was subsequently cast into $55-\mu \mathrm{m}$ thick green sheets using the doctor-blade method. These sheets were printed with Ni internal electrodes, stacked at $15 \mathrm{MPa}$ and $50^{\circ} \mathrm{C}$ to form a ceramic block, and cut into rectangular blocks $(3.8 \mathrm{~mm} \times 1.6 \mathrm{~mm})$. Subsequently, the binder was removed by heating at $330^{\circ} \mathrm{C}$ in air. The samples were sintered in an aluminum tube at $1190^{\circ} \mathrm{C}$ for $0.5,1,2,4$ and $6 \mathrm{~h}$ (S1, S2, S3, S4, and S5, respectively) in a reducing atmosphere $\left(3 \% \mathrm{H}_{2} / \mathrm{N}_{2}\right)$ at a $200{ }^{\circ} \mathrm{C} / \mathrm{h}$ heating/cooling rate. 
The bulk densities of the sintered specimens were measured using the Archimedes method. The surface microstructure of the as-sintered ceramics was observed by scanning electron microscopy (SEM; TESCAN MIRA3 EasyProbe, Czech). The mean grain size of the ceramic materials was estimated with the line-intersection method. The sintered BTN ceramics were re-oxidized at $800^{\circ} \mathrm{C}$ for $1 \mathrm{~h}$ in air, and the surfaces were rubbed with an In-Ga alloy (60:40) to form the electrode. The resistance was measured using a digital multimeter, while the temperature dependent-resistance was measured in a temperature-programmable furnace (ZWX-B, Huazhong University of Science and Technology, China) at a $1.6^{\circ} \mathrm{C} / \mathrm{min}$ heating rate ranging between 25 and $250{ }^{\circ} \mathrm{C}$.

\section{Results and Discussion}

\subsection{Microstructure of the Ceramics}

Figure 1 shows the microstructure of the BTN ceramics sintered at $1190^{\circ} \mathrm{C}$ for $0.5-6 \mathrm{~h}$ in a reducing atmosphere. The microstructure of the specimens, specially the grain size, was affected by the sintering time. As shown in Figures 1 (a-e), the mean grain size of the S1, S2, S3, S4, and S5 ceramics were $0.86,0.99,1.21,1.49$, and $1.54 \mu \mathrm{m}$, respectively. The different grain sizes obtained may be explained by differences in the grain growth rates. The grain size increased with the sintering time.
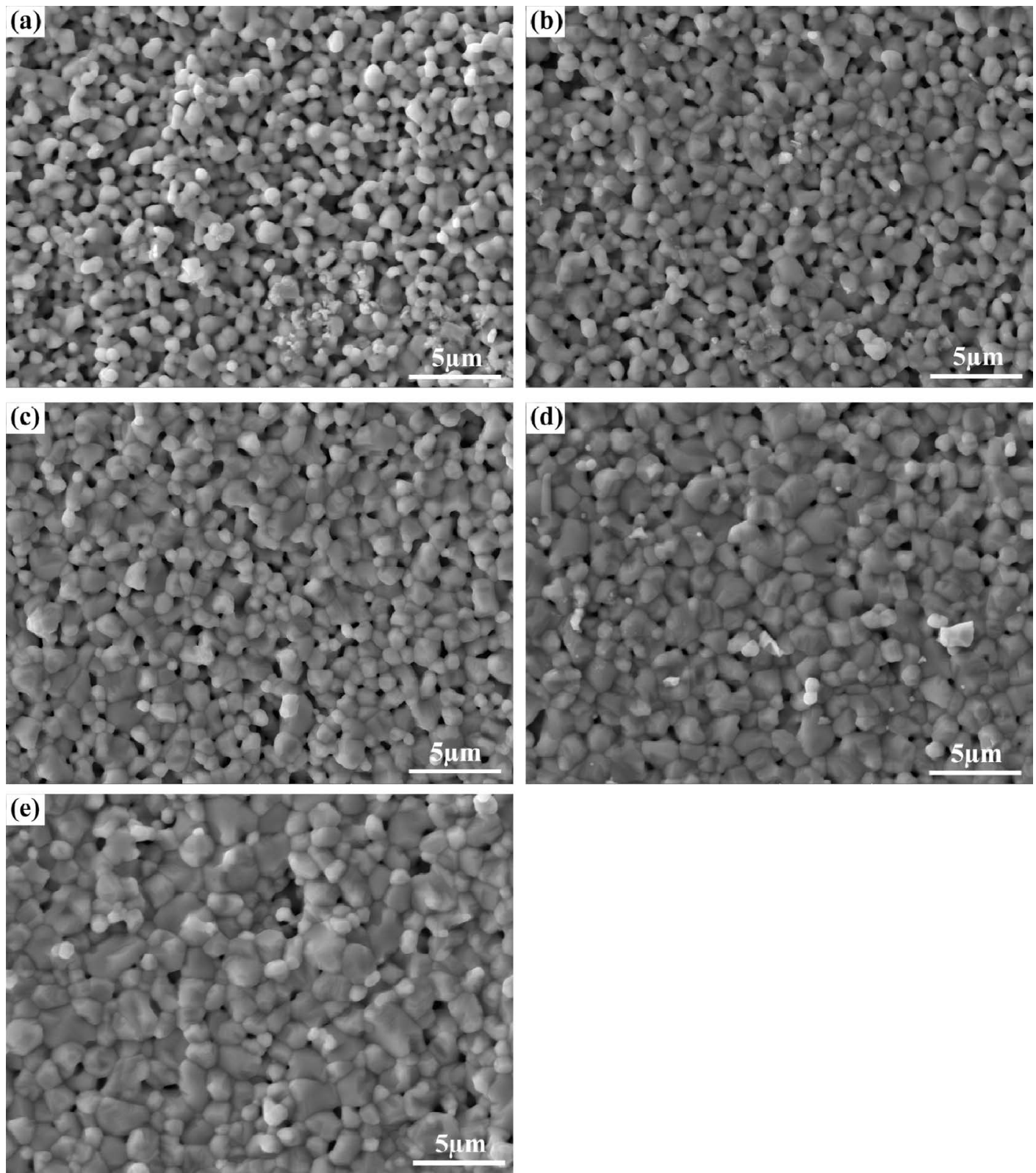

Figure 1. The SEM micrograph on the surfaces of the as-sintered specimens sintered at $1190{ }^{\circ} \mathrm{C}$ with different sintering time; (a) $0.5 \mathrm{~h}$, (b) $1 \mathrm{~h}$, (c) $2 \mathrm{~h}$, (d) $4 \mathrm{~h}$, (e) $6 \mathrm{~h}$. 


\subsection{Influence of the Sintering Time on the Electrical Properties}

The resistance jump ratio $\left[\mathrm{Lg}\left(\mathrm{R}_{\max } / \mathrm{R}_{\text {min }}\right)\right]$ and the $\mathrm{RT}$ resistance of the BTN ceramics are shown in Figure 2 as a function of the firing time. The RT resistance of the specimens re-oxidized (air, $800^{\circ} \mathrm{C}, 1 \mathrm{~h}$ ) after being reductively sintered $\left(1190{ }^{\circ} \mathrm{C}, 2 \mathrm{~h}\right)$ decreased with the sintering time increasing from 0.5 to $6 \mathrm{~h}$. The corresponding jumping ratio increased initially and decreased thereafter with the sintering time $(0.5-6 \mathrm{~h})$. The optimal resistance jump ratio was obtained for a sintering time of $2 \mathrm{~h}$. This optimal resistance jump ratio increased 3.60 times, and the RT resistance was $0.14 \Omega$.

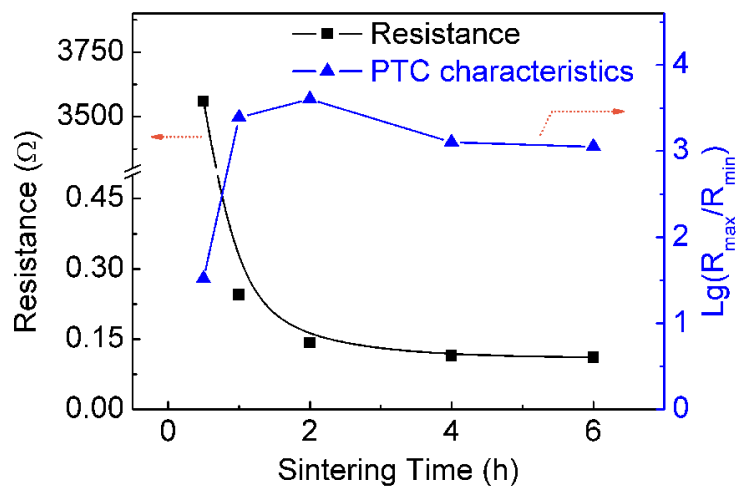

Figure 2. The room-temperature resistance and the jumping ratio are as a function of the sintering time.

In addition, the relative densities of the ceramics increased with the sintering time (Figure 3). The $\mathrm{S} 1$ and $\mathrm{S} 5$ samples showed relative densities of 79.8 and $91.0 \%$, respectively. The relative density of S1 was significantly lower than that of S5. As shown in Figure 1, these can be explained in terms of the void content of the ceramic surface. Thus, according to the following equation: $V_{o}^{*}+1 / 2 O_{2}+2 e^{\prime} \rightarrow 0_{0}, \mathrm{~S} 1$ can absorb a higher number of oxygen atoms from air than S5. Therefore, the amount of electrons in S1 was significantly lower than that of S5. Thus, the decrease in resistance can not be explained exclusively by the formation of oxygen vacancies, but also by the increase in the relative densities.

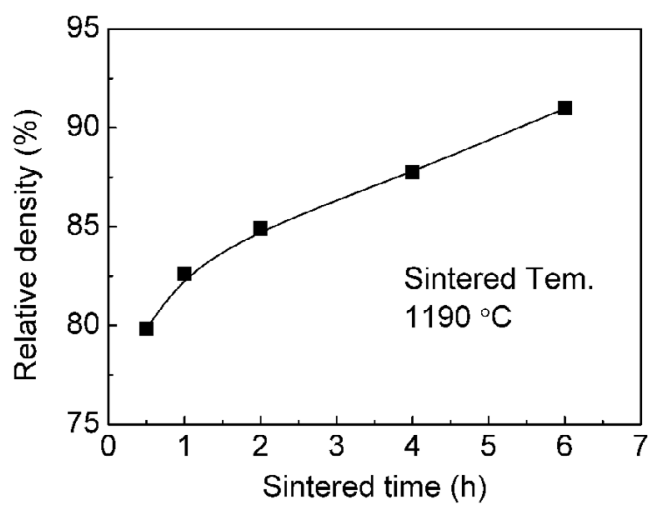

Figure 3. The relative densities of the ceramics are as a function of the sintering time.

\subsection{Influence of the Sintering Time on the PTCR Effect}

The influence of the sintering time on the PTCR characteristics of BTN ceramics is shown in Figure 2 and 4. The PTCR effect increased first and decreased thereafter with the sintering time. Moreover, the samples re-oxidized at $800^{\circ} \mathrm{C}$ for $1 \mathrm{~h}$ after being fired at $1190{ }^{\circ} \mathrm{C}$ for $2 \mathrm{~h}$ exhibited a remarkable PTCR effect. The porous structure (Figure 1) and relative densities (ca. 84.9\%) of the ceramics fired at $1190{ }^{\circ} \mathrm{C}$ can account for the observed results. The oxygen atoms are easily absorbed at the grain boundaries. Thus, the grain boundaries will be oxidized during the annealing treatment, increasing the resistance and the barrier height in these regions ${ }^{8}$. According to the Heywang-Jonker model ${ }^{2-4}$, the PTCR effect can be considered a grain-boundary effect. Herein, the PTCR effect was enhanced because of the development of a grain-boundary barrier.

Alternatively, according to the Arrhenius equation, the resistivity is given by the following formula ${ }^{14}$ :

$$
\rho=\rho_{0} \exp \left(E_{a} / k T\right)
$$

where $\rho_{0}$ is a constant, $\rho$ is the resistivity, $E_{a}$ is the activation energy, $T$ is the absolute temperature, and $\mathrm{k}$ is the Boltzmann constant. Therefore, the slope $(\lambda)$ of the Arrhenius plot $(\ln \rho$ versus $T^{I}$ ) was introduced, and the slope could be estimated from Eq. 1 with the following formula:

$$
E_{a}=\mathrm{k} \lambda
$$

Figure 5 shows the Arrhenius plots ( $\ln \rho$ versus 1000/T) for the BTN samples shown in Figure 4. As shown in Table 1, the activation energies calculated from Eq. 2 for the BTN ceramics fired ranged from 0.29 to $0.97 \mathrm{eV}$ with the sintering time $(0.5-6 \mathrm{~h})$. Shorter sintering times resulted in lower activation energies, leading to lower diffusion coefficients of the atoms through the matrix. However, long sintering times favored atomic diffusion because of the high activation energy. In addition, as in the case of the PCTR effect, the activation energy reached a maximum with the sintering time. Meanwhile, the potential-barrier height (e $\left.\phi_{0}\right)$ was estimated from the $E_{a}$ when the Fermi level $\left(E_{F}\right)$ of the grain boundary reached the interface of an accepter level ${ }^{15}$. According to the Heywang-Jonker model ${ }^{4-6}$, the potential-barrier height should follow the formula:

$$
e \phi_{0}=E_{a}-E_{F}
$$

The PTCR effect of the ceramics re-oxidized at $800^{\circ} \mathrm{C}$ for $1 \mathrm{~h}$ after being fired at $1190{ }^{\circ} \mathrm{C}$ for $2 \mathrm{~h}$ was enhanced. According to Eq. (3), the potential-barrier height was maximized for these samples, and this can explain these results. 
Table 1. Activation energy of the BTN samples, sintered at $1190{ }^{\circ} \mathrm{C}$ for different times and reoxidized at $800^{\circ} \mathrm{C}$ for $1 \mathrm{~h}$.

\begin{tabular}{cccccc}
\hline \multirow{2}{*}{ Samples } & \multicolumn{5}{c}{ Sintering time $(\mathrm{h})$} \\
\cline { 2 - 6 } & 0.5 & 1 & 2 & 4 & 6 \\
\hline$|\lambda|\left(10^{3} \mathrm{~K}^{-1}\right)$ & 3.34 & 10.5 & 11.29 & 9.97 & 8.44 \\
$E_{a}(\mathrm{eV})$ & 0.29 & 0.91 & 0.97 & 0.86 & 0.73 \\
\hline
\end{tabular}

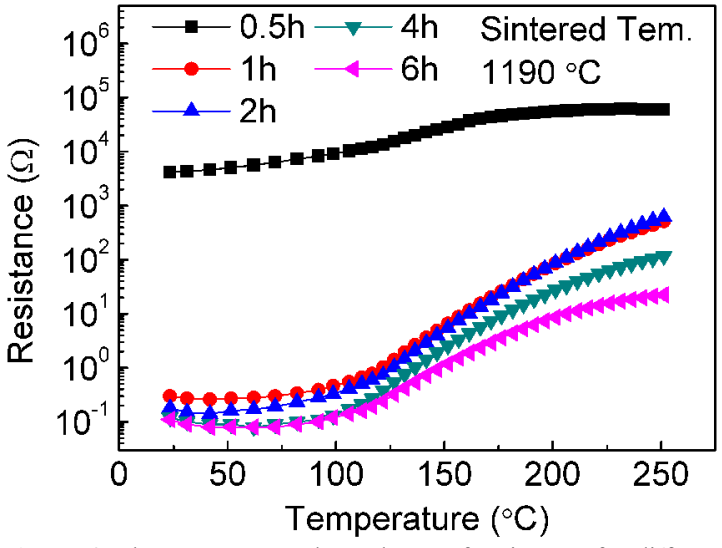

Figure 4. The temperature dependence of resistance for different sintering time.

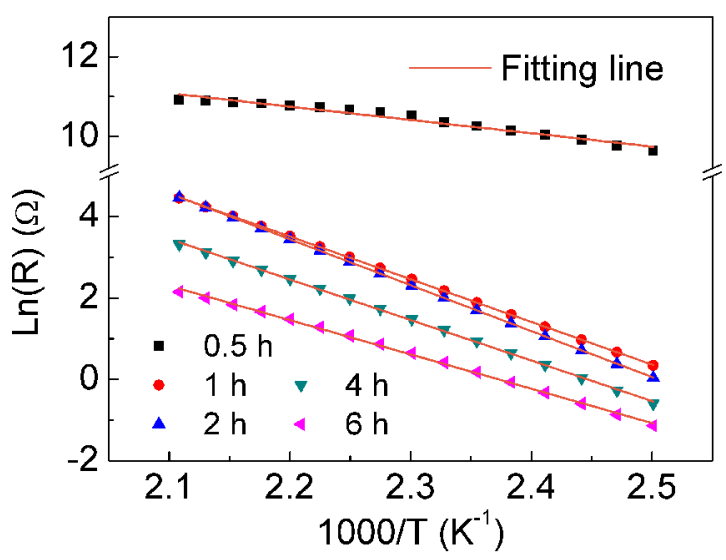

Figure 5. Arrhenius plots of $\operatorname{lnR}$ against $10^{3} / \mathrm{T}$ for $\mathrm{BTN}$ samples were reoxidized at $800^{\circ} \mathrm{C}$ for $1 \mathrm{~h}$ after sintering at $1190^{\circ} \mathrm{C}$ for different time.

\section{Conclusions}

In present work, the influence of the sintering time on the electrical and the PTCR properties of BTN ceramics fired using the reduction/re-oxidation method was investigated. The relative densities of the samples increased with the sintering time. Moreover, the RT resistance of the BTN ceramics decreased fast with the sintering time and increased slowly thereafter. The resistance jump ratio increased first and decreased thereafter with the sintering time. The BTN ceramics re-oxidized at 800 ${ }^{\circ} \mathrm{C}$ for $1 \mathrm{~h}$ after being reductively sintered at $1900{ }^{\circ} \mathrm{C}$ for $2 \mathrm{~h}$ showed superior PTCR characteristics. Thus, these samples showed increased (by 3.6 times) resistance jumps and a low $\mathrm{RT}$ resistance of $0.14 \Omega$. In addition, the experimental results indicated that the activation energy varied from 0.29 to 0.97 $\mathrm{eV}$ with the sintering time.

\section{Acknowledgements}

This work was financially supported by the National Natural Science Foundation of China (No. 51402258), the Natural Science Foundation of Guangdong Province (No. 2015A030313706), the Science and Technology Planning Project of Guangdong Province (No. 2014A010105056), the Characteristic Creative Project in University of Guangdong Province (No. 2016KTSCX152), the Science and Technology Planning Project of Zhaoqing City (No. 2015B010402003), the Youth Fund of Zhaoqing University (No. 201529).

\section{References}

1. Chung YK, Choi SC. Effects of the Re-oxidation Temperature and Time on the PTC Properties of Sm-doped $\mathrm{BaTiO}_{3}$. Journal of the Korean Ceramic Society. 2009;46(3):330-335.

2. Mancini MW, Paulin Filho PI. Direct observation of potential barriers in semiconducting barium titanate by electric force microscopy. Journal of Applied Physics. 2006;100(0):104501104503.

3. Li ZC, Zhang H, Zou XD, Bergman B. Synthesis of Sm-doped $\mathrm{BaTiO}_{3}$ ceramics and characterization of a secondary phase. Materials Science and Engineering: B. 2005;116(1):34-39.

4. Heywang W. Bariumtitanat als sperrschichthalbleiter. SolidState Electronics. 1961;3(1):51-58.

5. Heywang W. Resistance Anomaly in Doped Barium Titanate. Journal of the American Ceramic Society. 1964;47(10):484490.

6. Jonker GH. Some aspects of semiconducting barium titanate. Solid-State Electronics. 1964;7(12):895-903.

7. Cheng XX, Zhou DX, Fu QY, Gong SP, Zhao DC. Influence of sintering conditions on the electrical properties and the PTCR effect of the multilayer $\mathrm{Ba}_{1.005}\left(\mathrm{Ti}_{1-\mathrm{x}} \mathrm{Nb}_{\mathrm{x}}\right) \mathrm{O}_{3}$ ceramics with $\mathrm{Ni}$ internal electrode. Journal of Materials Science: Materials in Electronics. 2012;23(12):2202-2209.

8. Cheng XX, Zhou DX, Fu QY, Gong SP, Qin YX. Effect of reoxidation annealing on the PTCR behavior of multilayer $\mathrm{Nb}^{5+}$-doped $\mathrm{BaTiO}_{3}$ ceramics with $\mathrm{Ni}$ internal electrode. Journal of Physics D: Applied Physics. 2012;45(38):385306.

9. Lin TF, Hu CT, Lin IN. Influence of Stoichiometry on the Microstructure and Positive Temperature Coefficient of Resistivity of Semiconducting Barium Titanate Ceramics. Journal of the American Ceramic Society. 1990;73(3):531-536.

10. Lu YY, Lai CH, Tseng TY. Effect of Soaking Time on the Temperature Coefficient of Resistivity of Semiconducting Barium Titanate PTCR Ceramics. Journal of the American Ceramic Society. 1994;77(9):2461-2464. 
11. Al-Allak HM, Russell GJ, Woods J. The effect of annealing on the characteristics of semiconducting $\mathrm{BaTiO}_{3}$ positive temperature coefficient of resistance devices. Journal of Physics D: Applied Physics. 1987;20(12):1645-1651.

12. Ho IC, Fu SL. Effect of Reoxidation on the Grain-Boundary Acceptor-State Density of Reduced $\mathrm{BaTiO}_{3}$ Ceramics. Journal of the American Ceramic Society. 1992;75(3):728-730.

13. Langhammer HT, Makovec D, Pu YP, Abicht HP, Drofenik M. Grain boundary reoxidation of donor-doped barium titanate ceramics. Journal of the European Ceramic Society. 2006;26(14):2899-2907.
14. Cheng XX, Zhou DX, Fu QY, Gong SP. PTCR Effect of Chip Type $\mathrm{Ba}_{1.005-x} \mathrm{Sm}_{x} \mathrm{TiO}_{3}$ Ceramics prepared by Reduction Sintering-Reoxidation Method. Transactions of the Indian Ceramic Society. 2012;71(4):189-194.

15. Hayashi K, Yamamoto T, Ikuhara Y, Sakuma T. Formation of Potential Barrier Related to Grain-Boundary Character in Semiconducting Barium Titanate. Journal of the American Ceramic Society. 2000;83(11):2684-2688. 